\title{
PERCEPÇÃO DE ALUNOS DO ENSINO FUNDAMENTAL DA ESCOLA FRANÇSCO DE SOUZA RAMOS, QUANTO À PRESERVAÇÃO E ECONOMIA DE ÁGUA
}

\author{
Allem Duarte Lisboa ${ }^{1}$; Fabrício Marinho Lisbôa ${ }^{2}$; Clarissa Mendes Knoechelmann³ Geiso \\ Rafael Fonseca Oliveira ${ }^{4}$. \\ ${ }^{1}$ Discente da Faculdade de Ciências Exatas e Naturais (FACEN) da Universidade Federal do Pará (UFPA), bolsista \\ PROEX, allem.durlis@ hotmail.com \\ ${ }^{2}$ Discente do curso de Agronomia da Faculdade de Ciências Agrárias de Marabá (FCAM) da Universidade Federal do \\ Pará (UFPA), bolsista PROEX, fabriciomarinho87@yahoo.com \\ ${ }^{3}$ Prof ${ }^{a}$ Assistente I da Faculdade de Ciências Agrárias de Marabá (FCAM) da Universidade Federal do Pará (UFPA),, \\ clarissa@ufpa.br \\ ${ }^{4}$ Mestre em Química Analítica/UFPA, geisorafael@ufpa.br
}

RESUMO: A escassez de água tornou-se um dos graves problemas mundiais. Nos últimos anos tem-se pensado sobre fontes alternativas de água como água da chuva e as chamadas águas cinzas. Porém, além de novas alternativas, a educação ambiental é condição necessária para modificar um quadro de crescente degradação socioambiental e junto a ela, a percepção ambiental é fundamental para o reconhecimento do saber e do que condiciona os comportamentos de um indivíduo ou um grupo em relação ao meio ambiente. O objetivo deste trabalho foi avaliar a percepção de alunos do quarto e quinto ano de escola do ensino fundamental, quanto à preservação e economia de água. Desenvolveu-se atividades com crianças do quarto e quinto ano da Escola Municipal de Ensino Fundamental Francisco de Souza Ramos em fevereiro de 2011 com palestra utilizando apresentação em Powerpoint. Ao final da palestra, aplicou-se questionários com perguntas objetivas e subjetivas. Das 79 crianças $70,8 \%$ perceberam a real distribuição da água na Terra e $67 \%$ responderam que é necessário preservar este recurso. Em relação à atividades que visem a economia, 92,4\% tiveram consciência destes recursos. Assim como, $86 \%$ responderam que água pode ser reutilizada e 75,9\% responderam que utilizariam um filtro biológico. Desta forma, os alunos demonstraram elevada percepção do que seria a economia de água e a preservação deste insumo.

PALAVRAS-CHAVE: educação ambiental, escassez de água, fontes alternativas, percepção ambiental.

\section{PERCEPTION OF STUDENTS OF ELEMENTARY EDUCATION SCHOOL FRANCISCO DE SOUZA RAMOS, AS TO THE PRESERVATION AND WATER SAVING}

\begin{abstract}
Water shortage has become one of the serious global problems. In recent years it has been thought about alternative sources of water like rainwater and greywater. However, in addition to new alternatives, environmental education is a necessary condition for modifying a framework of growing socio-environmental degradation and with it, environmental awareness is crucial for the recognition of knowledge and that affects the behavior of an individual or group in relation the environment. The aim of this study was to evaluate the students' perception of the fourth and fifth year of elementary school, for the preservation and saving water. Developed activities with the children of the fourth and fifth years of the Francisco de Souza Ramos Elementary School in February 2011 with a lecture using PowerPoint presentation. At the end of the lecture was applied questionnaires with objective and subjective questions. Of the 79 children $70.8 \%$ realize to the real distribution of water on Earth and $67 \%$ responded that it is necessary to preserve this resource. In relation to activities aimed at the economy, $92.4 \%$ were aware of these resources. As well as $86 \%$ responded that water can be reused and $75.9 \%$ said they would use a biological filter. Thus, students
\end{abstract}


demonstrated a high sense of what would be saving water and the preservation of this input.

KEY-WORDS: alternative sources; environmental education; environmental perception; water scarcity.

\section{INTRODUÇÃO}

A escassez de água tornou-se um dos graves problemas mundiais e vem aumentando devido a vários fatores como a poluição hídrica, o uso desordenado, o desperdício, o crescimento da demanda e a gradativa diminuição de sua disponibilidade (PETERS et al., 2006). A dificuldade de obtenção de água nas grandes cidades e os custos crescentes de captação, tratamento e transporte agravados pela crescente degradação dos mananciais, vem apontando para a necessidade de conservação e uso racional deste insumo (RAPOPORT, 2004).

Neste sentido, nos últimos anos tem-se pensado sobre fontes alternativas de água, associadas ao uso de águas de chuva ou até mesmo a reutilização de águas servidas geradas e tratadas nas residências, para fins menos nobres como a rega de jardins, lavação de calçadas e descargas em sanitários. Chamadas de “águas cinzas”, estas águas podem ser compostas pela água já utilizada em pias de banheiro e cozinha, chuveiros, lavagem de roupa ou qualquer água utilizada na residência com exceção das águas provenientes de bacias sanitárias.

Apesar dessas novas alternativas, Leff (2001) ressaltou que é impossível resolver os crescentes e complexos problemas ambientais e reverter suas causas sem que ocorra uma mudança radical nos sistemas de conhecimento. Assim, a educação ambiental assume cada vez mais uma função transformadora, na qual a coresponsabilização dos indivíduos torna-se um objetivo essencial para promover o desenvolvimento sustentável (JACOBE, 2003). Portanto, a educação ambiental é condição necessária para modificar um quadro de crescente degradação socioambiental.

Junto a conscientização, a percepção ambiental é fundamental para o reconhecimento do saber e do que condiciona os comportamentos de um indivíduo ou um grupo em relação ao meio ambiente (BUTZKE; PEREIRA; NOEBAUER, 2001). As percepções não são simples sensações, mas são definidas como o conhecimento que o ser humano adquire através do contato com o meio em que vive e são influenciadas por fatores como personalidade, cultura e condições sócio-culturais (OLIVEIRA, 1983; VARGAS et al., 2006). Neste contexto, o objetivo deste trabalho foi avaliar a percepção de alunos do quarto e quinto ano de escola do ensino fundamental, quanto à preservação e economia de água. 


\section{MATERIAL E MÉTODOS}

$\mathrm{O}$ trabalho foi realizado em função do projeto de extensão "Reaproveitamento do Elemento Água como Alternativa de Economia Hídrica”, o qual visa a reutilização de águas servidas, águas cinzas, após sua filtragem em filtros de areia, além de promover a educação ambiental através de palestras e oficinas. Desenvolveu-se atividades com crianças do quarto e quinto ano da Escola Municipal de Ensino Fundamental Francisco de Souza Ramos em fevereiro de 2011. No total de 79 crianças com médias de idade de nove e dez anos, respectivamente. A escola foi escolhida em função dos responsáveis pela mesma, Direção e Secretária de Educação municipal, aceitarem contribuir com o estudo.

Primeiramente realizou-se no auditório da escola uma palestra com os alunos sobre o tema "Uso de Águas Cinzas", em que foi abordado principalmente os assuntos: distribuição de água no planeta, preservação do elemento água, atividades que podem auxiliar na economia da água, reciclagem de água e utilização de filtros biológicos em outros locais do país. Para a palestra, utilizouse apresentação em Powerpoint, a qual foi adequada à média de idade dos alunos.

Ao final da apresentação aplicou-se questionário (Apêndice A) com cinco questões a respeito dos itens apresentados e a aceitação destas crianças em relação à utilização de filtros biológicos, o qual conteve quatro questões objetivas e uma subjetiva.

\section{RESULTADOS E DISCUSSÃO}

Quando indagadas sobre a quantidade de água doce no planeta, 70,8\% das crianças perceberam a real distribuição deste recurso e apontaram que no planeta Terra há mais água salgada, proveniente de oceanos e mares.

Sobre a preservação da água doce existente no planeta, $67 \%$ responderam que é necessário preservar este recurso. Segundo Tontini (2010), as crianças percebem a água como um bem de grande importância para a coletividade e requer de cada indivíduo uma postura de respeito frente ao uso deste recurso natural e reconhecem a água como sinônimo de vida, podendo sua extinção causar grandes danos.

A respeito de atividades simples do cotidiano que podem auxiliar na economia hídrica, como a utilização de baldes e não de mangueiras na lavagem do carro, 92,4\% tiveram consciência destes recursos e de sua importância. Contrapondo a Fernandes et al. (2005), os quais destacaram que, a sociedade, de uma forma geral, tem a consciência de praticar ações que redundem no uso racional da água, entretanto, em sua grande maioria, desconhece as formas práticas de atender a tal objetivo.

Durante a palestra, os alunos foram questionados se tinham alguma informação sobre a reciclagem de água e sua reutilização. Neste momento demonstram não ter nenhuma opinião formada a este respeito e nem conhecimento sobre o que seria a reciclagem de água. Porém, após a explanação, 86\% 
responderam que água pode ser reutilizada, ou como dita reciclada. Neste sentido, de acordo com Sem Gupta (1993) e Costa et al. (2007) a percepção está associada ao ambiente particular na qual vivem as suas práticas sócio-econômicas, dessa maneira as experiências adquiridas sobre a água pode revelar dados singulares sobre a relação do manejo e conservação deste recurso, assim, fica claro que, provavelmente, não havia a utilização da prática de reciclagem de água em suas residências.

$\mathrm{Na}$ questão subjetiva, na qual se verificou entre elas a aceitação do filtro biológico em sua residência, $75,9 \%$ responderam que utilizariam um filtro biológico. E utilizariam porque este ajuda a melhorar a qualidade das águas cinzas e a utilização destas ajuda na economia de água.

\section{CONCLUSÕES}

Após a palestra os alunos demonstraram elevada percepção do que seria a economia de água e a preservação deste insumo. Assim como, conhecimento sobre práticas que atendam tal objetivo. Em relação aos filtros biológicos, o mesmo teve grande aceitação pelos alunos que conseguiram entender sua função.

\section{AGRADECIMENTOS}

Á Pró-Reitoria de Extensão da Universidade Federal do Pará. Direção da Escola Municipal de Ensino Fundamental Francisco de Souza Ramos e Secretaria
Municipal de Educação de Marabá.

\section{REFERÊNCIAS}

BUTZKE, I. C.; PEREIRA, G. R.; NOEBAUER, D. A. Sugestão de indicadores para avaliação do desempenho das atividades educativas do sistema de gestão ambiental SGA da Universidade Regional de Blumenau. Rev. eletrônica Mestr. Educ. Ambient., Rio Grande, v. 13, p. 144 -157, 2001.

COSTA, T.V. et al. Brincando entre igapós: a água na percepção das crianças da Reserva de Desenvolvimento Sustentável Tupé, Manaus/AM. Rev. Eletrônica Mestr. Educ. Ambient., Rio Grande, v. 18, p. 100-115, 2007.

FERNANDES, R.S. et al. Percepção Ambiental de Segmentos Sócio-Econômicos da Sociedade frente à problemática do uso racional da Água. Vitória: NEPA, 2005. (Relatório de Pesquisa)

JACOBE, P. Educação Ambiental, cidadania e sustentabilidade. Cadernos de Pesquisa, n. 118, p. 189-205, 2003.

LEFF, E. Epistemologia ambiental. São Paulo: Cortez, 2001.

OLIVEIRA, L. A percepção da qualidade ambiental: A ação do homem e a qualidade ambiental. In: Machado, M.L.C.P. (Org.). Qualidade ambiental: indicadores quantitativos e perceptivos. Rio Claro: Associação dos Geógrafos/ Câmara Municipal, 1983. 
PETERS, M. R. et al. Quantificação e caracterização de águas cinzas em uma residência. SIMPÓSIO INTERNACIONAL DE QUALIDADE AMBIENTAL, 5. 2006, Porto Alegre. Anais... Porto Alegre: ABES, 2006.

Disponível em:<http://www.gesad.ufsc.br/download/Pete rs\%20et\%20al[1].\%202006\%20-

\%20SIQA.pdf>. Acesso em: 7 mar 2011.

RAPOPORT, B. Águas cinzas: caracterização, avaliação financeira e tratamento para reuso domiciliar e condominial. 2004. 72 f. Dissertação (Mestrado em Saúde Pública) - Fundação Oswaldo Cruz. Rio de Janeiro - RJ, 2004.

SEM GUPTA, S. Percepção da população de Ahmedabad. Revista de geografia, São
Paulo, v. 1993.

TONTINI, S. Representações Sociais Sobre o Tema "Água" Reveledas em Poemas por Alunos de $6^{\text {a }}$ Série do Ensino Fundamental em Medicilândia, Pará. In: SEMANA DE INTEGRAÇÃO DAS CIÊNCIAS AGRÁRIAS, 10. Altamira, 2010. Anais... Altamira, UFPA, 2010. p. 212 - 219.

VARGAS, M.C. et al. Água \& Cidadania: percepção social dos problemas de quantidade, qualidade e custo dos recursos hídricos em duas bacias hidrográficas do interior paulista. In: ENCONTRO DA ASSOCIAÇÃO NACIONAL DE PÓSGRADUAÇÃO E PESQUISA EM AMBIENTE E SOCIEDADE, 1. Indaiatuba, 2002. Anais... Indaiatuba, 2002. p. 1 - 16 